\title{
Geographic Information and Technologies in Academic Libraries: An ARL Survey of Services and Support
}

\section{ABSTRACT}

One hundred fifteen academic libraries, all current members of the Association of Research Libraries $(A R L)$, were selected to participate in an online survey in an effort to better understand campus usage of geographic data and geospatial technologies, and how libraries support these uses. The survey was used to capture information regarding geographic needs of their respective campuses, the array of services they offer, and the education and training of geographic information services department staff members. The survey results, along with review of recent literature, were used to identify changes in geographic information services and support since 1997, when a similar survey was conducted by ARL. This new study has enabled recommendations to be made for building a successful geographic information service center within the campus library that offers a robust and comprehensive service and support model for all geographic information usage on campus.

\section{INTRODUCTION}

In June 1992, the ARL in partnership with Esri (Environmental Systems Research Institute) launched the GIS (Geographic Information Systems) Literacy Project. This project sought to "introduce, educate, and equip librarians with the skills necessary" to become effective GIS users and to learn how to provide patrons with "access to spatially referenced data in all formats." 1 Through the implementation of a GIS program, libraries can provide "a means to have the increasing amount of digital geographic data become a more useful product for the typical patron."2

In 1997, five years after the GIS Literacy Project began, a survey was conducted to elucidate how ARL libraries support patron GIS needs. The survey was distributed to 121 ARL members for the purpose of gathering information about GIS services, staffing, equipment, software, data, and support these libraries offered to their patrons. Seventy-two institutions returned the survey, a $60 \%$ response rate. At that time, nearly three-quarters (74\%) of the respondents affirmed that their library administered some level of GIS services. ${ }^{3}$ This indicates that the GIS Literacy Project had an evident positive impact on the establishment of GIS services in ARL member libraries.

Since then, it has been recognized that the rapid growth of digital technologies has had a tremendous effect on GIS services in libraries. ${ }^{4}$ We acknowledge the importance of assessing

Ann L. Holstein (ann.holstein@case.edu) is GIS Librarian at Kelvin Smith Library, Case Western Reserve University, Cleveland, Ohio. 
how geographic services in academic research libraries have further evolved over the past 17 years in response to these advancing technologies as well as the increasingly demanding geographic information needs of their user communities.

\section{METHOD}

For this study, 115 academic libraries, all current members of ARL as of January 2014, were invited to participate in an online survey in an effort to better understand campus usage of geographic data and geospatial technologies and how libraries support these uses. Similar in nature to the 1997 ARL survey, the 2014 survey was designed to capture information regarding geographic needs of their respective campuses, the array of services, software. and support the academic libraries offer, and the education and training of geographic information services department staff members. Our aim was to be able to determine the range of support patrons can anticipate at these libraries and ascertain changes in GIS library services since the 1997 survey.

A cross-sectional survey was designed and administered using Qualtrics, an online survey tool. It was distributed in January 2014 via email to the person identified as the subject specialist for mapping and/or geographic information at each ARL member academic library. When the survey closed after two weeks, 54 institutions had responded to the survey. This accounts for $47 \%$ participation. Responding institutions are listed in the appendix.

\section{RESULTS}

\section{Software and Technologies}

We were interested in learning about what types of geographic information software and technologies are currently being offered at academic research libraries. Results show that $100 \%$ of survey respondents offer GIS software/mapping technologies at their libraries, 36\% offer remote sensing software (to process and analyze remotely sensed data such as aerial photography and satellite imagery), and 36\% offer Global Positioning System (GPS) equipment and/or software. Nearly all (98\%) said that their libraries provide Esri ArcGIS software, with 83\% also providing access to Google Maps and Google Earth, and 35\% providing QGIS (previously known as Quantum GIS). Smatterings of other GIS, remote-sensing, and GPS products are also offered by some of the libraries, although not in large numbers (see table 1 for full listing).

The fact that nearly all survey respondents offer ArcGIS software at their libraries comes as no surprise. ArcGIS is the most commonly provided mapping software available in academic libraries, and in 2011, it was determined that 2,500 academic libraries were using Esri products. ${ }^{5}$ Esri software was most popular in 1997 as well, undoubtedly because they offered free software and training to participants of the GIS Literacy Project. ${ }^{6}$ 


\begin{tabular}{|lcc|}
\hline Software/Technology & Type & $\begin{array}{c}\text { \% of Providing } \\
\text { Libraries }\end{array}$ \\
\hline Esri ArcGIS & GIS & 98 \\
\hline Google Maps/Earth & GIS & 83 \\
\hline QGIS & GIS & 35 \\
\hline AutoCad & GIS & 19 \\
\hline ERDAS IMAGINE & Remote Sensing & 19 \\
\hline GRASS & GIS & 15 \\
\hline ENVI & Remote Sensing & 15 \\
\hline GeoDa & GIS & 6 \\
\hline PCI Geomatica & Remote Sensing & 6 \\
\hline Garmin Map Source & GPS & 6 \\
\hline SimplyMap & GIS & 4 \\
\hline Trimble TerraSync & GPS & 4 \\
\hline
\end{tabular}

Table 1. Geographic Information Software/Mapping Technologies Provided at ARL Member Academic Libraries (2014)

Google Maps and Google Earth, launched in 2005, have quickly become very popular mapping products used at academic libraries-a close second only to Esri ArcGIS. In addition to being free, their ease of use, powerful visualization capabilities, "customizable map features and dynamic presentation tools" make them attractive alternatives to commercial GIS software products. ${ }^{7}$

Since 1997, many software programs have fallen out of favor. MapInfo, Idrisi, Maptitude, and Sammamish Data Finder/Geosight Pro were GIS software programs listed in the 1997 survey results that are not used today at ARL member academic libraries. ${ }^{8}$ Instead, open source software such as QGIS, GRASS, and GeoDa are growing in popularity. They are free to use and their source code may be modified as needed.

GPS equipment lending can be very beneficial to students and campus researchers who need to collect their own field research locational data. The 2014 survey found that $30 \%$ of respondents loan recreational GPS equipment at their libraries and 10\% loan mapping-grade GPS equipment. The high cost of mapping-grade GPS equipment (several thousand dollars) may be a barrier for some libraries; however, this is the type of equipment recommended in best-practice methods for gathering highly accurate GPS data for research. In addition to expense, complexity of operation is another consideration. While it is "fairly simple to use a recreational GPS unit," a certain level of advanced training is required for operating mapping-grade GPS equipment. ${ }^{9} \mathrm{~A}$ designated staff member may need to take on the responsibility of becoming the in-house GPS expert and routinely offer training sessions to those interested in borrowing mapping-grade GPS equipment.

\section{Location}


At $36 \%$ of responding libraries, the geographic information services area is located where the paper maps are (map department/services); 19\% have separated this area and designated it as a geospatial data center, GIS, or data services department; 13\% integrate it with the reference department; and just $4 \%$ of libraries house the GIS area in government documents. Table 2 lists all reported locations for this service area. Not surprisingly, in 1997, government documents (39\%) was just as popular a location for this service area as within the map department (43\%). ${ }^{10}$ Libraries identified government documents as a natural fit, keeping GIS services within close proximity to spatial data sets recently being distributed by government agencies, most notably the US Government Printing Office (GPO). These agencies had made the decision to distribute "most data in machine readable form,"11 including the 1990 Census data as Topographically Integrated Geographic Encoding and Referencing (TIGER) files. ${ }^{12}$ GIS technologies were needed to access and most effectively use information within these massive spatial datasets.

Location

\begin{tabular}{|lcc|}
\hline Map Department/Services & 43 & 36 \\
\hline Government Documents & 39 & 4 \\
\hline Reference & 10 & 13 \\
\hline Geospatial Data Center, GIS, or Data Services & 3 & 19 \\
\hline Not in any one location & - & 9 \\
\hline Digital Scholarship Center & - & 6 \\
\hline Combined Area (i.e., Map Dept. \& Gov. Docs.) & - & 6 \\
\hline
\end{tabular}

Table 2. Location of the Geographic Information Services Area within the Library (1997 and 2014)

At $59 \%$ of responding libraries, geographic information software is available on computer workstations in a designated area, such as within the map department. However, many do not restrict users by location and have the software available on all computer workstations throughout the library (37\%) or on designated workstations distributed throughout the library (33\%). A small percentage (7\%) loan laptops to patrons with the software installed, allowing full mobility throughout the entire library space.

\section{Staffing}

Most professional staff working in the geographic information services department hold one or more postbaccalaureate advanced degrees. Of 113 geographic services staff at responding libraries, 65\% had obtained an MA/MS, MLS/MLIS, or PhD; 43\% have one advanced degree, while $22 \%$ have two postbaccalaureate degrees. Half (50\%) hold an MLS/MLIS, 31\% hold an MA/MS, and $6 \%$ hold a PhD. Nearly one-third (31\%) have obtained a BA/BS as their highest educational degree, $3 \%$ had a two-year technical degree, and 2\% had only earned a GED or high school diploma. In 1997, 84\% of GIS librarians and specialists at ARL libraries had an MLS degree. ${ }^{13}$ At that time, the incumbent was most often recruited from within the library to assume this new role, 
whereas today's GIS professionals are just as likely to come from nonlibrary backgrounds, bringing their expertise and advanced geographic training to this nontraditional librarian role.

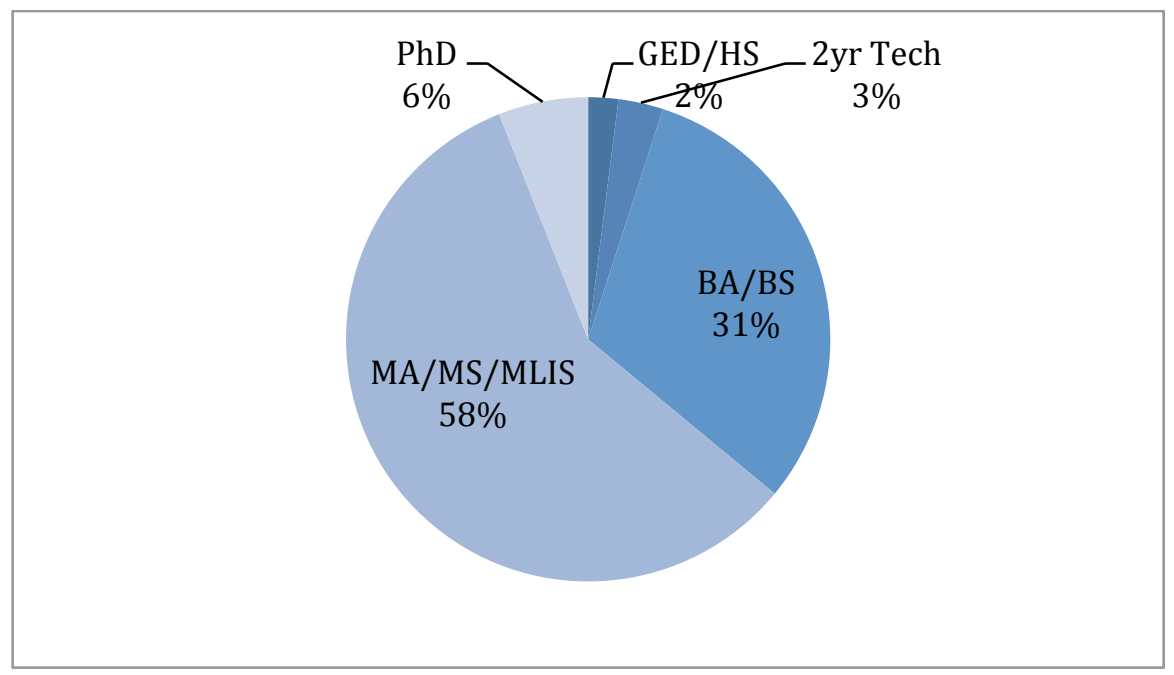

Figure 1. Highest Educational Degree of Geographic Services Staff (2014)

On average, this department is staffed by two professional staff members and three student staff. Student employees can be a terrific asset, especially if they have been previously trained in GIS. Students are likely to be recruited from departments that are the heaviest GIS users at the university (i.e., geography, geology). Some libraries have implemented "co-op" programs where students can receive credit for working at the GIS services area. These dual-benefit positions are quite lucrative to students. ${ }^{14}$

\section{Campus Users}

In a typical week during the course of a semester, responding libraries each serve approximately sixteen GIS users, four remote sensing users, and three GPS users. These users may obtain assistance from department staff either in-person or remotely via phone or email.

On average, undergraduate and graduate students compose the majority (75\%) of geographic service users (32\% and 43\%, respectively). Faculty members compose $14 \%$ of the users, followed by staff (including postdoctoral researchers) at 7\%. Some institutions also provide support to public patrons and alumni (4\% and 1\%, respectively). In 1997, it was estimated that on average, $63 \%$ of GIS users were students, $22 \%$ were faculty, $8 \%$ were staff, and $8 \%$ were public. ${ }^{15}$ 


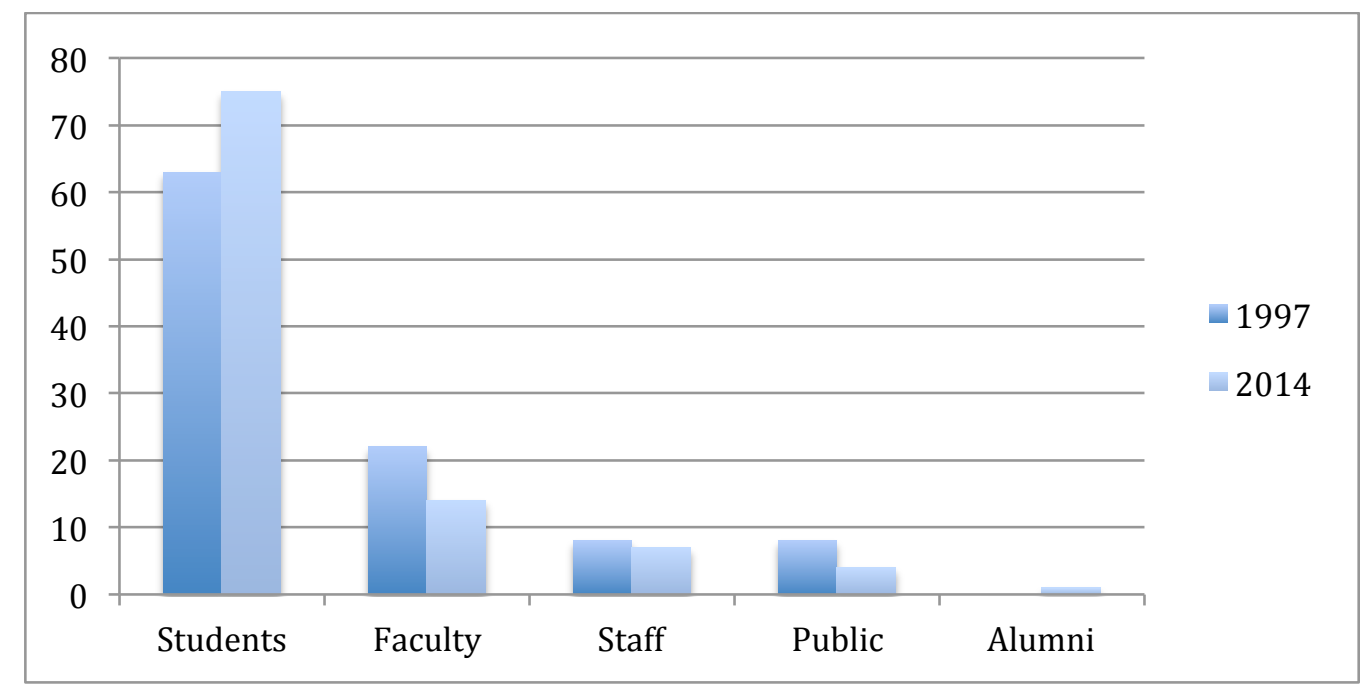

Figure 2. Comparison of the Percentage of Geographic Service Users by Patron Status (1997 and 2014)

The top three departments that use GIS software at ARL campuses are Environmental Science/Studies, Urban Planning/Studies, and Geography. The most frequent remote sensing software users come from the departments of Environmental Science/Studies, Geography, and Archaeology. GPS equipment loan and software usage is most popular with the departments of Environmental Science/Studies, Geography, Biology/Ecology and Archaeology (see table 3 for full listing). Some departments are heavy users of all geographic technologies, while others have shown interest in only one. For example, the departments of Psychology and Medicine/Dentistry have used GIS but have expressed little or no interest in using remote-sensing or GPS technologies.

\section{Support and Services}

The campus community is supported by library staff in a variety of ways with regards to GIS, remote-sensing, and GPS technology and software use. Nearly all (94\%) libraries provide assistance using the software for specific class assignments and projects, and $78 \%$ are able to provide more in-depth research project consultations. More than one-quarter (27\%) of reporting libraries will make custom GIS maps for patrons, although there may be a charge depending on the library, project, and patron type (10\%). Most (90\%) offer basic use and troubleshooting support; however, just 39\% offer support for software installation, and 55\% offer technical support for problems such as licensing issues and turning on extensions. The campus computing center or information technology services (ITS) at ARL institutions most likely fields some of the software installation and technical issues rather than the library, thus accounting for the lower percentages.

A variety of software training may be offered to the campus community through the library; $80 \%$ of responding libraries make visits to classes to give presentations and training sessions, $69 \%$ host workshops, $47 \%$ provide opportunities for virtual training courses and tutorials, and $4 \%$ offer certificate training programs. 


\begin{tabular}{|lccc|}
\hline Department & GIS & Remote Sensing & GPS \\
\hline Anthropology & 24 & 10 & 8 \\
\hline Archaeology & 24 & 14 & 13 \\
\hline Architecture & 24 & 1 & 6 \\
\hline Biology/Ecology & 32 & 10 & 13 \\
\hline Business/Economics & 23 & 1 & 3 \\
\hline Engineering & 18 & 9 & 11 \\
\hline Environmental Science/Studies & 41 & 22 & 16 \\
\hline Forestry/Wildlife/Fisheries & 21 & 12 & 10 \\
\hline Geography & 35 & 22 & 15 \\
\hline Geology & 31 & 12 & 10 \\
\hline History & 27 & 2 & 2 \\
\hline Information Sciences & 14 & 1 & 0 \\
\hline Nursing & 8 & 1 & 2 \\
\hline Medicine/Dentistry & 9 & 0 & 0 \\
\hline Political Science & 25 & 3 & 5 \\
\hline Psychology & 4 & 0 & 0 \\
\hline Public Health/Epidemiology/ Biostatistics & 30 & 3 & 9 \\
\hline Social Work & 2 & 0 & 1 \\
\hline Sociology & 22 & 0 & 3 \\
\hline Soil Science & 17 & 5 & 4 \\
\hline Statistics & 8 & 3 & 0 \\
\hline Urban Planning/Studies & 36 & 7 & 9 \\
\hline
\end{tabular}

Table 3. Number of ARL Libraries Reporting Frequent Users of GIS, Remote-Sensing, or GPS Software and Technologies from a Campus Department (2014)

Often, the library is not the only place people can go to obtain software support and training on campus. Most (86\%) responding libraries state that their university offers credit courses, and $41 \%$ of campuses have a GIS computer lab located elsewhere on campus that may be utilized. ITS is available for assistance at $29 \%$ of the universities, and continuing education offers some level of training and support at $14 \%$ of campuses.

\section{Data Collection and Access}

Most (85\%) of responding libraries collect geographic data and allow an annual budget for it. "Libraries that have invested money in proprietary software and trained staff members will tend to also develop and maintain their own collection of data resources." ${ }^{\prime 16}$ Of those collecting data, $26 \%$ spend less than $\$ 1,000$ annually, $15 \%$ spend between $\$ 1,000$ and $\$ 2,499,17 \%$ spend between $\$ 2,500$ and $\$ 5,000$, while $41 \%$ spend more than $\$ 5,000$. In $1997,79 \%$ of libraries spent less than $\$ 2,000$ annually, and only $9 \%$ spent more than $\$ 5,000 .{ }^{17}$ 


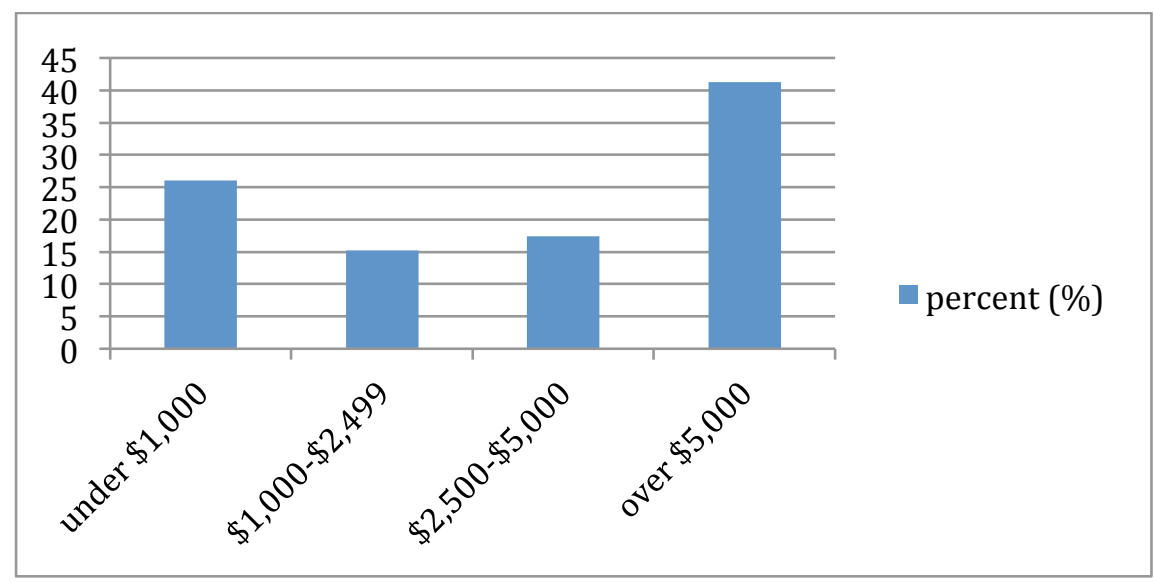

Figure 3. Annual budget allocations for geographic data (2014)

A dramatic shift has occurred over the years with budget allocations for data sets. No longer are academic libraries just collecting free government data sets as was typically the case back in 1997, but they are investing much more of their materials budget into building up the geographic data collection for their users.

Data is made accessible to campus users in a variety of ways. A majority (84\%) offer data via remote access or download from a networked campus computer, using a virtual private network (VPN) or login. More than half (62\%) of responding libraries provide access to data from workstations within the library, and 64\% lend CD-ROMs.

Roughly one-quarter (26\%) of responding libraries provide users with storage for their data. Of those, $29 \%$ have a dedicated geographic data server, $14 \%$ use the main library server, $29 \%$ point users to the university server or institutional repository, and 36\% allow users to store their data directly onto a library computer workstation hard drive.

\section{Internal Use of GIS in Libraries}

Geographic information technologies may be used internally to help patrons navigate the library's physical collections and efficiently locate print materials. Of the survey respondents, $60 \%$ use GIS for map or air photo indexing, $27 \%$ use the technology to create floor maps of the library building, and $15 \%$ use it to map the library's physical collections. "The use of GIS in mapping library collections is one of the non-traditional but useful applications of GIS."18 GIS can be used to link library materials to simulated views of floor maps through location codes. ${ }^{19}$ This enables patrons to determine the exact location of library material by providing them with item "location details such as stacks, row, rack, shelf numbers, etc." 20 The GIS system can become a useful tool for collection management and can be a tremendous time-saver for patrons, especially those unfamiliar with the cataloging system or collection layout.

\section{DISCUSSION}

Recommendations for Building a Successful Geographic Information Service Center 
The geographic information services area is often a blend of the traditional and modern. It can extend to paper maps, atlases, GPS equipment, software manuals, large-format scanners, printers, and GIS. GIS services may include a cluster of computers with GIS software installed, an accessible collection of GIS data resources, and assistance available from the library staff. The question for academic libraries today is no longer "whether to offer GIS services but what level of service to offer." ${ }^{21}$ Every university has different GIS needs, and the library must decide how it can best support these needs. There is no set formula for building a geographic information service center because each institution "has a different service mission and user base."22 Every library's GIS service program will be designed with its unique institutional needs in mind; however, they each will incorporate some combination of hardware, software, data, and training opportunities provided by at least one knowledgeable staff member. ${ }^{23}$

"GIS represents a significant investment in hardware, software, staffing, data acquisition, and ongoing staff development. Either new money or significant reallocation is required."24 Establishing new or enhancing GIS services in the library requires the "serious assessment of longterm support and funding needs." 25 Commitment of the university as a whole, or at least support from senior administration, "library administration, and related campus departments" is crucial to its success. ${ }^{26}$ Receiving "more funding will mean more staff, better trained staff, a more in-depth collection, better hardware and software, and the ability to offer multiple types of GIS services." ${ }^{27}$

Once funding for this endeavor has been secured, it is of utmost importance to recruit a GIS professional to manage the geographic information service center. To be most effective in this position, the incumbent should possess a graduate degree in GIS or geography; however, depending on what additional responsibilities would be required of the candidate (i.e., reference, cataloging, etc.) a second degree in library science is strongly recommended. This staff member should possess mapping and GIS skills, which include experience with Esri software and remote sensing technologies. Employees in this position may be given a job titles such as "GIS specialists, GIS/data librarians, GIS/map librarians, digital cartographers, spatial data specialists, and GIS coordinators." 28

With the new staff member on board, hereafter referred to as "GIS specialist," decisions such as what software to provide, which data sets to collect, and what types of training and support to offer to the campus can be made. Consulting with research centers and academic departments that currently use or are interested in using GIS and remote sensing technologies is a good place to learn about software, data, and training needs and to determine the focus and direction of the geographic information services department. ${ }^{29}$ Campus users often come from academic departments that "have neither staff nor facilities to support GIS," and "may only consist of one or two faculty and a few graduate students. These GIS users need access to software, data, and expertise from a centralized, accessible source of research assistance, such as the library." ${ }^{30}$

At minimum, Esri ArcGIS, Google Maps and Google Earth should be supported, with additional remote sensing or open source GIS software depending on staff expertise and known campus 
needs. When purchasing commercial software licenses, such as for Esri ArcGIS, discounts for educational institutions are usually available. Additionally, negotiating campus-wide software licenses may be a good option to consider as the costs are usually far less than purchasing individual or floating licenses. Costs for campus-wide licensing are typically determined by fulltime equivalent (FTE) students enrolled at the university.

Facilitating "access to educational resources such as software tools and applications, how-toguides for data and software," and tutorials is crucial. ${ }^{31}$ The GIS specialist must be familiar with how GIS software can be used by many disciplines, the availability of "training courses or tutorials, sources or extensible GIS software, and hundreds of software and application books." 32 Tutorials may be provided direct from a software vendor (i.e., Esri Virtual Campus) or developed in-house by the GIS specialist. Creating "GIS tutorials on short, task-based techniques such as georeferencing or geocoding" and making them readily available online or as a handout may save time having to repeatedly explain these techniques to patrons. ${ }^{33}$

Geospatial data collection development is a core function of the geographic information services department. To effectively develop the data collection, the GIS specialist must fully comprehend the needs of the user community as well as possess a "fundamental understanding of the nature and use of GIS data." 34 This is often referred to as "spatial literacy." 35 It is crucial to keep abreast of "recent developments, applications, and data sets." 36

The GIS specialist will spend much more time searching for and acquiring geographic data sets than selecting and purchasing traditional print items such as maps, monographs, and journals for the collection. A budget should be established annually for the purchase of all geographic materials, both print and digital. A great challenge for the specialist is to acquire data at the lowest cost possible. While a plethora of free data is available online from government agencies and nonprofit organizations, other data, available only from private companies, may be quite expensive because of the high production costs. A collection development policy should be created that indicates the types of materials and data collected and specifies geographic regions, formats, and preferred scales. ${ }^{37}$ The needs of the user community must be carefully considered when establishing the policy.

The expertise of the GIS specialist is needed not only to help patrons locate the appropriate geographic data, but also to use the software to process, interpret, and analyze it. "Only the few library patrons that have had GIS experience are likely to obtain any level of success without intervention by library staff"; ${ }^{8}$ thus, for any mapping program installed on a library computer, "staff must have working knowledge of the program" and must be able to provide support to users..$^{39}$ Furthermore, the GIS specialist must be able to train patrons to use the software to complete common tasks such as file format conversion, data projection, data manipulation, and geoprocessing. These geospatial technologies involve a steep learning curve, and unfortunately "hands-on training options outside the university are often cost-prohibitive" for many. ${ }^{40}$ The campus community requires training opportunities to be both convenient and inexpensive. 
Teaching hands-on geospatial technology workshops, from basic to the advanced, is fundamental to educating the campus community. Workshops will "vary from institution to institution, with some offering students an introduction to mapping and others focusing on specific features of the program, such as georeferencing, geocoding, and spatial analysis. Some also offer workshops that are theme specific," such as "Working with census data" or "Digital elevation modeling." 41 Custom workshops or training sessions can be developed to meet a specific campus need, tailored for a specific class in consult with an instructor, or designed especially for other library staff.

\section{Today's Geographic Information Service Center}

The academic map librarian from the 1970s or 1980s would hardly recognize todays' geographic information service center. What was once a room of map cases and shelves of atlases and gazetteers is now a bustling geospatial center. Computers, powerful GIS and remote-sensing technologies, GPS devices, digital maps, and data are now available to library patrons. Every library surveyed provides GIS software to campus users, and 85\% also actively collect GIS and remotely sensed data. With the assistance of expertly trained library staff, users with no or limited experience using geospatial technologies are enabled to analyze spatial data sets and create custom maps for coursework, projects, and research. Nearly all surveyed libraries (94\%) have staff that can assist students specifically with software use for class assignments and projects, while $90 \%$ provide assistance with more generalized use of the software. A majority of libraries also offer a variety of software training sessions, workshops, and give presentations to the campus community. All this is made possible through the library's commitment to this service area and the availability of highly trained professional staff, most who hold a masters or doctoral degree. The library has truly established itself as the go-to location on campus for spatial mapping and analysis. This role has only strengthened in the years since the launch of the ARL GIS Literacy Project in 1992.

\section{REFERENCES}

1. D. Kevin Davie et al., comps., SPEC Kit 238: The ARL Geographic Information Systems Literacy Project (Washington, DC: Association of Research Libraries, Office of Leadership and Management Services, 1999), 16.

2. Ibid., 3 .

3. Ibid., i.

4. Abraham Parrish, "Improving GIS Consultations: A Case Study at Yale University Library," Library Trends 55, no. 2 (2006): 328, http://dx.doi.org/10.1353/lib.2006.0060.

5. Eva Dodsworth, Getting Started with GIS: A LITA Guide (New York: Neal-Schuman, 2012), 161.

6. Davie et al., SPEC Kit 238, i. 
7. Eva Dodsworth and Andrew Nicholson, "Academic Uses of Google Earth and Google Maps in a Library Setting," Information Technology \& Libraries 31, no. 2 (2012): 102, http://dx.doi.org/10.6017/ital.v31i2.1848.

8. Davie et al., SPEC Kit 238, 8.

9. Gregory H. March, "Surveying Campus GIS and GPS Users to Determine Role and Level of Library Services," Journal of Map \& Geography Libraries 7, no. 2 (2011): 170-71, http://dx.doi.org/10.1080/15420353.2011.566838.

10. Davie et al., SPEC Kit 238, 5.

11. George J. Soete, SPEC Kit 219: Transforming Libraries Issues and Innovation in Geographic Information Systems. (Washington, DC: Association of Research Libraries, Office of Management Services, 1997), 5.

12. Camila Gabaldón and John Repplinger, "GIS and the Academic Library: A Survey of Libraries Offering GIS Services in Two Consortia," Issues in Science and Technology Librarianship 48 (2006), http://dx.doi.org/10.5062/F4QJ7F8R.

13. Davie et al., SPEC Kit 238, 5.

14. Soete, SPEC Kit 219, 9.

15. Davie et al., SPEC Kit 238, 10.

16. Dodsworth, Getting Started with GIS, 165.

17. Davie et al., SPEC Kit 238, 9.

18. D. N. Phadke, Geographical Information Systems (GIS) in Library and Information Services (New Delhi: Concept, 2006), 36-37.

19. Ibid., 13.

20. Ibid., 74 .

21. Rhonda Houser, "Building a Library GIS Service from the Ground Up," Library Trends 55, no. 2 (2006): 325, http://dx.doi.org/10.1353/lib.2006.0058.

22. Melissa Lamont and Carol Marley, "Spatial Data and the Digital Library," Cartography and Geographic Information Systems 25, no. 3 (1998): 143, http://dx.doi.org/10.1559/152304098782383142. 
23. Carolyn D. Argentati, "Expanding Horizons for GIS Services in Academic Libraries," Journal of Academic Librarianship 23, no. 6 (1997): 463, http://dx.doi.org/10.1559/152304098782383142.

24. Soete, SPEC Kit 219, 11.

25. Carol Cady et al., "Geographic Information Services in the Undergraduate College: Organizational Models and Alternatives," Cartographica 43, no. 4 (2008): 249, http://dx.doi.org/10.3138/carto.43.4.239.

26. Houser, "Building a Library," 325.

27. R. B. Parry and C. R. Perkins, eds., The Map Library in the New Millennium (Chicago: American Library Association, 2001), 59-60.

28. Patrick Florance, "GIS Collection Development within an Academic Library," Library Trends 55, no. 2 (2006): 223, http://dx.doi.org/10.1353/lib.2006.0057.

29. Houser, "Building a Library," 325.

30. Ibid., 323.

31. Ibid., 322.

32. Parrish. "Improving GIS," 329.

33. Ibid, 336.

34 Florance, "GIS Collection Development," 222.

35. Soete, SPEC Kit 219, 6.

36. Dodsworth, Getting Started with GIS, 165.

37. Soete, SPEC Kit $219,8$.

38. Gabaldón and Repplinger, "GIS and the Academic Library."

39. Dodsworth, Getting Started with GIS, 164.

40. Houser, "Building a Library," 323.

41. Dodsworth, Getting Started with GIS, 161-62. 


\section{APPENDIX}

\section{Responding Institutions}

Arizona State University Libraries

Auburn University Libraries

Boston College Libraries

University of Calgary Libraries and Cultural Resources

University of California, Los Angeles, Library

University of California, Riverside, Libraries

University of California, Santa Barbara, Libraries

Case Western Reserve University Libraries

Colorado State University Libraries

Columbia University Libraries

University of Connecticut Libraries

Cornell University Library

Dartmouth College Library

Duke University Library

University of Florida Libraries

Georgetown University Library

University of Hawaii at Manoa Library

University of Illinois at Chicago Library

University of Illinois at Urbana-Champaign Library

Indiana University Libraries Bloomington

Johns Hopkins University Libraries

University of Kansas Libraries

McGill University Library

University of Manitoba Libraries

University of Maryland Libraries

Massachusetts Institute of Technology Libraries

University of Miami Libraries
University of Michigan Library

Michigan State University Libraries

University of Nebraska-Lincoln Libraries

New York University Libraries

University of North Carolina at Chapel Hill Libraries

North Carolina State University Libraries

Northwestern University Library

University of Oregon Libraries

University of Ottawa Library

University of Pennsylvania Libraries

Pennsylvania State University Libraries

Purdue University Libraries

Queen's University Library

Rice University Library

University of South Carolina Libraries

University of Southern California Libraries

Syracuse University Library

University of Tennessee, Knoxville, Libraries

University of Texas Libraries

Texas Tech University Libraries

University of Toronto Libraries

Tulane University Library

Vanderbilt University Library

University of Waterloo Library

University of Wisconsin-Madison Libraries

Yale University Library

York University Libraries 